\title{
THE EFFECTS OF FIRE ON BURROW-NESTING SEABIRDS PARTICULARLY SHORT-TAILED SHEARWATERS (PUFFINUS TENUIROSTRIS) AND THEIR HABITAT IN TASMANIA
}

\author{
by Nigel Brothers and Stephen Harris
}

(with three text-figures, four plates and an appendix)

\begin{abstract}
Brothers, N. \& Harris, S., 1999 (31:x): The effects of fire on burrow-nesting seabirds particularly short-tailed shearwaters (Puffinus tenuirostris) and their habitat in Tasmania. Pap. Proc. R. Soc. Tasm. 133(1): 15-22. https://doi.org/10.26749/rstpp.133.1.15

ISSN 0080-4703. Parks and Wildlife Service, Department of Primary Industries, Water and Environment, GPO Box 44A,

Hobart, Tasmania, Australia 7001.

The synchronised breeding habit of many seabird species makes them particularly vulnerable to fires in the nesting area. Post-fire recolonisation and soil formation were studied on Albatross Island, and observations from island rookeries of shearwaters, fairy prions and fairy penguins in eastern Bass Strait and elsewhere were used with a view to understanding the long-term impact of fires on seabird colonies in Tasmania.
\end{abstract}

Key Words: island vegetation, flora, Tasmania, fire, coast, rookeries, seabirds, soil depth, Puffinus tenuirostris, Bass Strait, habitat monitoring.

\section{INTRODUCTION}

Large populations of seabirds breed on islands around Tasmania and it is on these islands that wildfires frequently occur, mostly through vandalism, sometimes by accident. Deliberate burning by land managers also occurs.

It is difficult to understand fully the long-term effects of a fire on seabirds such as short-tailed shearwaters, planned destructive experiments in bird rookeries being unacceptable. The best chance of obtaining empirical data on fire effects is to establish plots in selected rookeries which can then be sites for data collection following any chance disturbance such as fire. The timing of the fire in relation to the stage of seabird breeding cycles will have different impacts on populations.

Several studies have examined the effects of soil nutrients, soil moisture and seabird activity in Australian rookeries (Gillham 1960a,b, Brown et al. 1993, Walsh et al. 1997). Documentation of the effects of fire on soils and vegetation in seabird rookeries is rare.

This study was made in the interests of understanding and, it is to be hoped, to reducing the long-term impact of fire on seabird colonies

\section{MATERIALS AND METHODS}

\section{Site Descriptions}

\section{Albatross Island study site}

Pre-fire vegetation

Albatross Island, in southwestern Bass Strait (fig. 1) has an area of 100 ha. Soils with $90 \%$ humus content are intermittently scattered between bare rock outcrops, in many places being only several centimetres deep but up to $0.5 \mathrm{~m}$ in gullyareas. Vegetation is dominated by succulents, particularly Disphyma crassifolium and Senecio lautus. Tetragonia implexicoma occurs sporadically over the island, especially amidst the protection of boulders. It was not a component of the pre-fire vegetation at the study site. Poa poiformis is dominant in many localities, particularly where soils are deep, and it is in such circumstances thatburrow-nestingseabirds are found in greatest abundance. Short-tailed shearwaters, Puffinus tenuirostris, are most abundant in this habitat, with small numbers of little penguin, Eudyptes minor, scattered throughout. Figure 2 indicates the location of colony $A$ and colony $B$ with respect to the effects of fire. Elsewhere, outside colonies A and B, fairy prions, Pachyptila turtur, are abundant, nesting in rock crevices and in burrows, as they are considerably less limited by the shallow soil depth here than the larger short-tailed shearwaters. Short-tailed shearwaters and little penguins do, however, nest outside colonies A and B but mostly in sparsely scattered burrows. There is a total of approximately 2000 short-tailed shearwater, 350 little penguin and 20000 fairy prion pairs nesting on the island.

Figure 2 also shows the location of shy albatross, Diomedea cauta, colonies. Albatrosses have reduced the whole of their colony to bare rocks as vegetation and soil are used in nestmound construction. This is most relevant to the extent of soil and vegetation elsewhere on the island, as Robinson (in Plomley 1966) originally observed the island as being "covered in birds" and Brothers (pers. obs.) plotted the former extent of the albatross colony as indicated by guanoencrusted rock, which encompasses colonies A and B. From this and the nesting habits of albatrosses as described, it is reasonable to assume that the vegetation and soils and, therefore, burrow-nesting seabirds in colonies A and B are of recent origin, approximately 100 years.

There are no introduced vertebrates on Albatross Island.

\section{Pre-fire burrow densities}

Before the 1982 fire (see below), short-tailed shearwater burrow density in colony A was $0.57 / \mathrm{m}^{2}$ (ten $2.5 \mathrm{~m}$ radius circular plots range $7-17$, mean 11.1 ). The total number of burrows in the $1250 \mathrm{~m}^{2}$ of colony was about 700 . Colony B pre-fire burrow density was $0.59 / \mathrm{m}^{2}$ (ten $2.5 \mathrm{~m}$ radius circular plots, range $6-13$, mean 11.5 ) or a total of about 350 burrows in $600 \mathrm{~m}^{2}$, which is the extent of this colony. Some nest sites included in the above figures at both colonies were in the base of matted Poa poiformis tussocks, there being insufficient depth of soil for burrowing. 


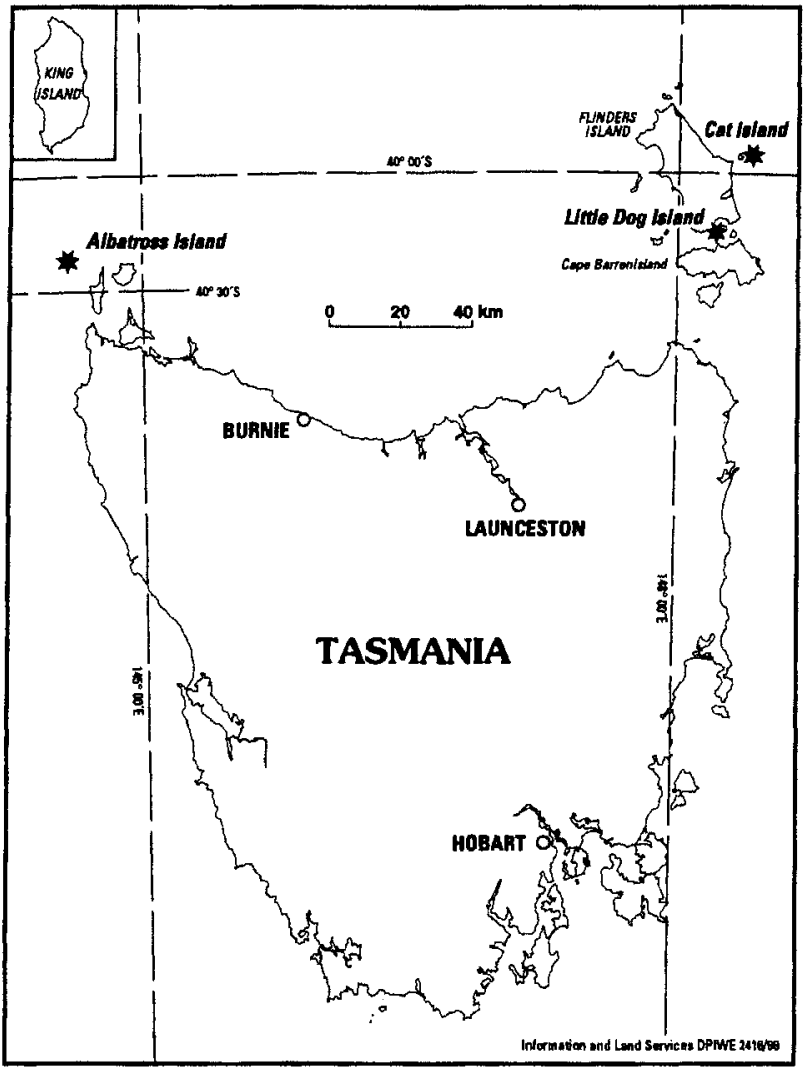

FIG. 1 - Locations of Albatross, Cat and Little Dog Islands.

\section{Fire description}

An accidentally lit fire in February 1982 burnt 20 ha in the north of Albatross Island (fig. 2). The fire self-extinguished after several days, but not before all vegetation had been destroyed and soil reduced to scorched patches a few millimetres deep, surrounded by bare rock (pl. 1). A ravine intersecting the island prevented more extensive destruction. Figure 2 shows the extent of the fire, Colony A being totally destroyed, Colony B unaffected. Apart from the destruction of shearwater, prion and penguin habitat, a potential longterm effect of the fire, seabirds present in their colonies at the time of the fire were incinerated. Penguin burrows could have contained chicks and some adults at the time and up to 100 individuals may have died. Fairy prion chicks fledge by early February so, apart from small numbers of adult prions that occasionally stay ashore in burrows, thousands of this species escaped destruction by only a matter of weeks. For short-tailed shearwaters the timing of the fire was not so favourable, as chicks would have been about one month old. Apart from the 700 in Colony A, another 200 are estimated to have died in the areas burnt. An unknown number of juvenile birds that are very active at this time of the year selecting nesting sites and mates frequently stay ashore during day time, as does the occasional adult breeding bird attending its chick, and not all would have escaped the fire.

\section{Other islands}

Little Dog Island (66 ha) is situated in Franklin Sound in the Furneaux Group. It is dominated by $P$. poiformis tussock grassland. Cat Island (49 ha) is low and grassy and its

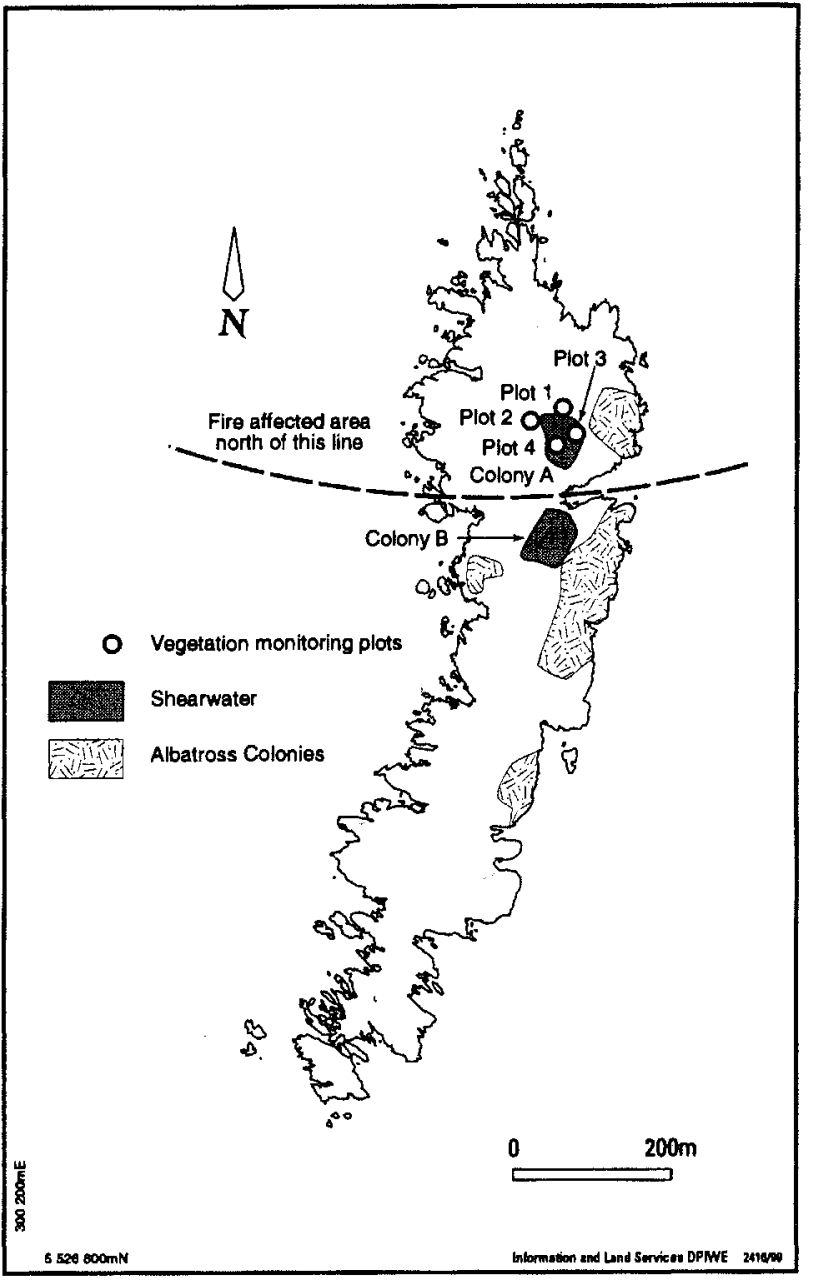

FIG. 2 - Albatross Island, showing locations of sampling plot sites, location of rookeries and extent of burnt area.

vegetation is also dominated by $P$. poiformis. It is a part of the Babel Group off the east coast of Flinders Island. Brief descriptions of other island rookeries around Tasmania are given in Naarding (1981).

\section{Sampling Methods}

\section{Albatross Island}

\section{Vegetation recovery}

To measure the recovery of vegetation and shearwater breeding, the corners of four $5 \mathrm{~m}^{2}$ plots were marked with PVC poles and assessed annually (in September) for changes in vegetation from 1982 (two measurement events) to 1990 and then again in 1998. The percentage cover of each plant species in each plot was assessed. Vegetation recovery Plot 2 was located away from shearwater habitation, Plot 1 was in peripheral shearwater colony habitat, whereas Plots 3 and 4 were in areas of highest pre-fire nesting density.

\section{Soil depth}

Soil depths were obtained by repeatedly positioning at random a steel spike throughout each area and measuring the length of the spike from ground surface to contact with rock. 


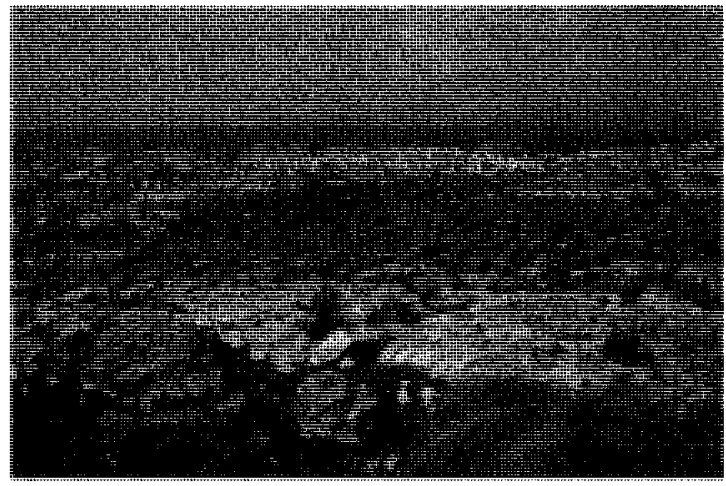

PLATE 2

Colony $A$ Albatross Island, vegetation recovery six years after the 1982 fire.

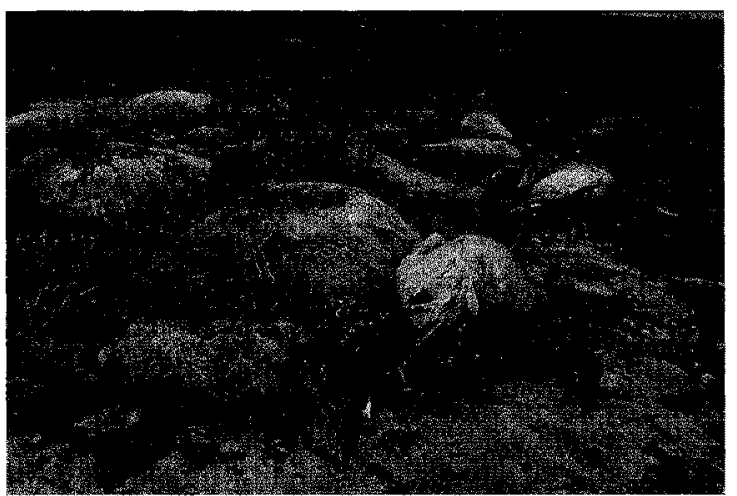

PLATE 4

Shearwaters and Gannets killed by fire, Cat Island, 1984.

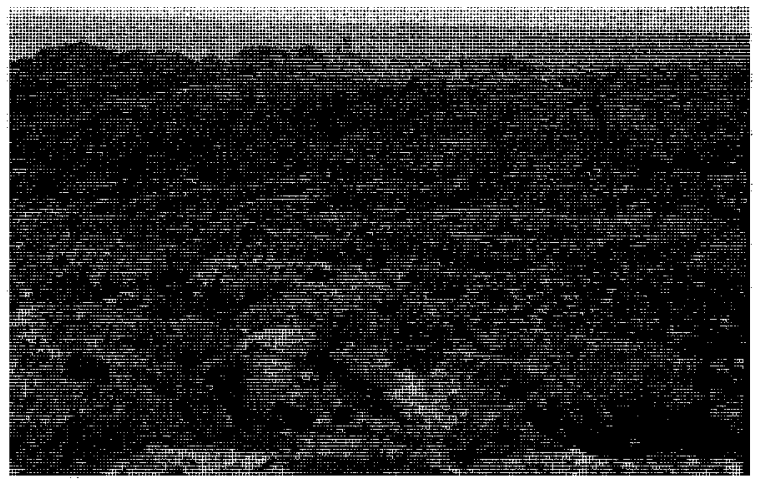

PLATE 1

Colony A Albatross Island, destruction by fire March 1982.

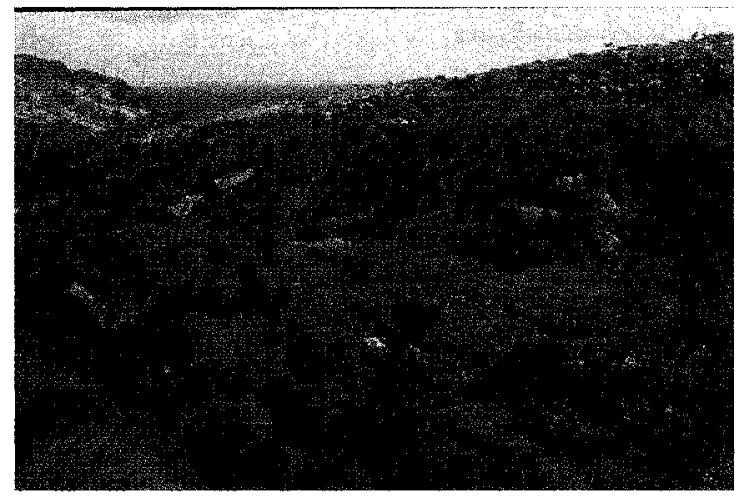

PLATE 3

Colony $B$ Albatross Island, habitat destruction due to excessive shearwater activity. 


\section{Nest densities}

Nesting densities were calculated from the number of burrow entrances counted within circular plots (radius $2.5 \mathrm{~m}$ ) randomly located through shearwater colonies. Searches of the plots were undertaken annually (in September, December and April) for shearwater occupancy and breeding success.

\section{Other islands}

Burrows were examined after fires on both Little Dog and Cat Islands in the Furneaux Group. Observational data were collected, enabling some comparisons between these islands and Albatross Island.

A published checklist (Naarding 1981) of shearwater colonies was used in assessing the number of rookeries which have been burned. The assessment was made from personal recollection, field notes and observations of physical evidence of fire.

\section{RESULTS}

\section{Post-fire Vegetation Recovery}

At all four sites, recolonisation to $100 \%$ cover of vegetation (fig.3) occurred by the six.th year, principally by Disphyma crassifolium and Senecio lautus. D. crassifolium is an excellent perennial ground-cover plant that would assist in soil stabilisation and provide shelter for other plant species that take longer to re-establish. This is apparently the case for $P$. poiformis, which is slower to re-establish but, having done so, is capable of displacing $D$. crassifolium and S. lautus (fig.3).

In the first two years following the fire, all plots had one or two very small patches of Pelargonium australe and Crassula sieberiana but these species subsequently disappeared, presumably due to encroachment of $D$. crassifolium. Elsewhere on the island, $C$. sieberiana is common but restricted to small patches in rock crevices and $P$. australe occurs as isolated scattered plants amongst $D$. crassifolium. Whilst $S$. lautus is even more adept at re-establishing than $D$. crassifolium, this species has a comparatively short spring growing season after which it dies back, again exposing soil to erosion. Colloquially known as "fire weed", this species flourishes after fire and also favours areas of high soil disturbance, for example, in and around shearwater colonies. Hence, in Plots 3 and 4 the re-emergence of this species coincides with renewed vigorous shearwater burrowing activity. It is anticipated that $S$. lautus will become codominant with Poa poiformis ultimately. Plot 2 was indistinguishable from unburnt, similar habitat on the island in its third year of regeneration with the relative abundance of $D$. crassifolium and $S$. lautus fluctuating annually. Vegetation recovery is portrayed in plate 2 .

\section{Post-fire Soil Regeneration}

As previously stated, it is not known what proportion of shearwaters in Colony $\mathrm{A}$, prior to the fire, were nesting in burrows dug in soil as opposed to nesting in matted $P$. poiformis. The average pre-fire soil depth is also not known, but in Colony B, which is very similar to pre-fire Colony A, shearwaters are able to use soil $150 \mathrm{~mm}$ or greater in depth for burrowing (provided $P$. poiformis is present to maintain soil stability). Thirty-one randomly selected points throughout Colony B averaged $189 \mathrm{~mm}$ soil depth (range $100-340 \mathrm{~mm}$ ).

Predicting when soil in Colony A will have reformed to similar depth is difficult because in 1989, when measurements were taken, the average soil depth in Plot 3 from 15 sites was $66 \mathrm{~mm}$ (range $25-105 \mathrm{~mm}$ ). Presumably, $P$. poiformis contributes most to the formation of soil in such localities owing to the nature of the plant, and this species had only become firmly established two years earlier. In 1998, the average soil depth in this plot was $71 \mathrm{~mm}$ (range 25-113 mm). In comparison, in Plot 1 , where $P$. poiformis was slow to establish, soil depth measured in 1989 averaged $39 \mathrm{~mm}$ from 15 measurement sites (range $15-75 \mathrm{~mm}$ ). Even after sixteen years, soil depth in plot 1 still averaged the same order, $32 \mathrm{~mm}$ (range $15-96 \mathrm{~mm}$ ).

The rate of soil build up is compounded by the contribution that increasing numbers of re-establishing nesting shearwaters will have to nutrient input and, therefore, plant growth rates (Brothers \& Harris, pers. obs.).

\section{Post-fire Shearwater Burrow Density}

Seven years after the fire, average burrow density was only $0.46 / \mathrm{m}^{2}$ with an occupancy rate of $48.5 \%, 16.2 \%$ less than the average occupancy rate (Skira \& Wapstra 1980).

Shearwaters first returned to Plots 3 and 4 at Colony A in September 1988. Whilst there was still insufficient soil to permit burrowing, $P$. poiformis had now become sufficiently well established to form a protective canopy with a dense matted base that was adequate for shearwaters to attempt nesting. Canopy height was now a uniform $200 \mathrm{~mm}$ but $400 \mathrm{~mm}$ where burrowing occurred.

In Plots 3 and 4, burrowing attempts were recorded amongst matted $P$. poiformis. However, only one egg was laid in one plot (Plot 3) and this subsequently disappeared, presumably because it still had insufficient concealment from predators such as Tasmanian raven (Corvus tasmanicus), pacific gulls (Larus pacificus) and silver gulls ( $L$. novaehollandiae). The incubating bird was only partially concealed in its burrow. In Plot 4 there was evidence of three burrowing attempts but no breeding followed.

The following season, there were six burrowing attempts in Plot 3, and three eggs were laid. From these, one chick successfully fledged, the first in eight breeding seasons. Plot 4 had three burrowing attempts with an egg laid in one and the chick successfully fledged. On pre-fire burrow density information, Plots 3 and 4 should each contain about 14 burrows which, based on information from Skira \& Wapstra (1980), should produce about seven chicks annually, significantly more than that recorded after eight breeding seasons following the fire. In 1989, four chicks were raised successfully from 50 attempts at burrowing throughout Colony A.

Penguins attempted to reuse all plots for nesting in the 1984 breeding season and did so successfully in Plots 3 and 4 from 1986 onward. This species is not strictly colonial in its nesting habits, so can take advantage of the smallest amount of suitable nesting habitat.

By 1989, only one pair of prions had re-established in Plot 4 and none in any other plot.

Shearwaters displaced by the fire also attempted to reestablish, but suitable habitat was not available. The invasion of shearwaters from Colony A to Colony B caused considerable damage to Colony B (pl. 3). Prior to the fire 
PLOT 1 (Peripheral to seabird colony)

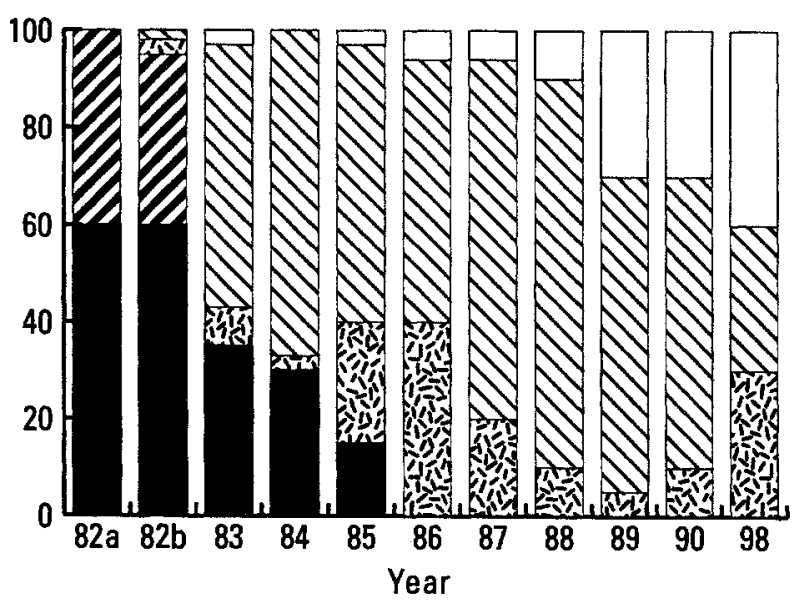

PLOT 3 (High density seabird colony)

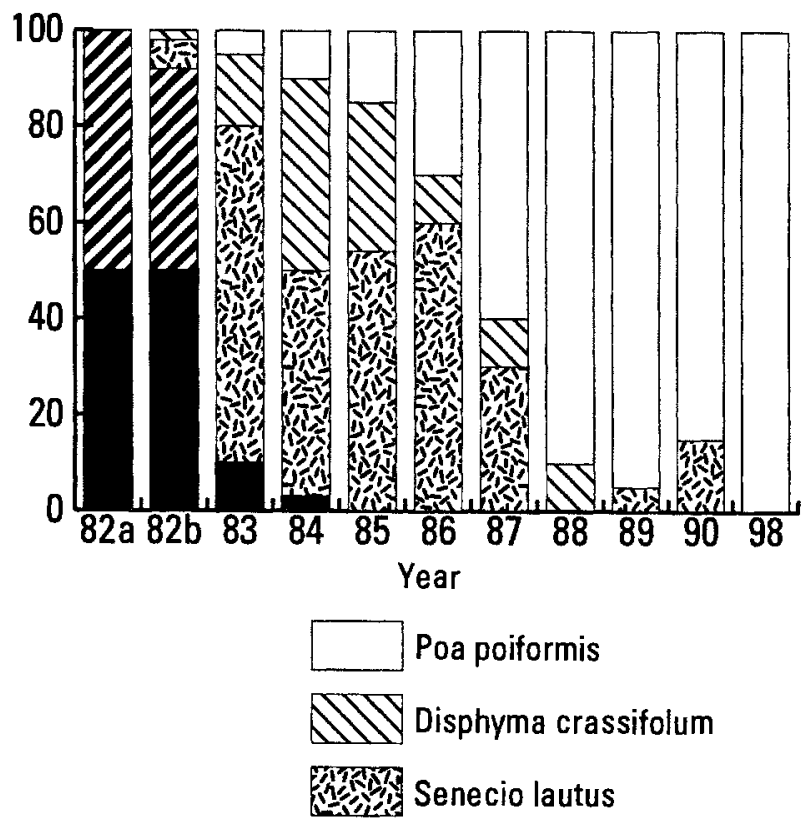

PLOT 2 (Away from seabird colony)

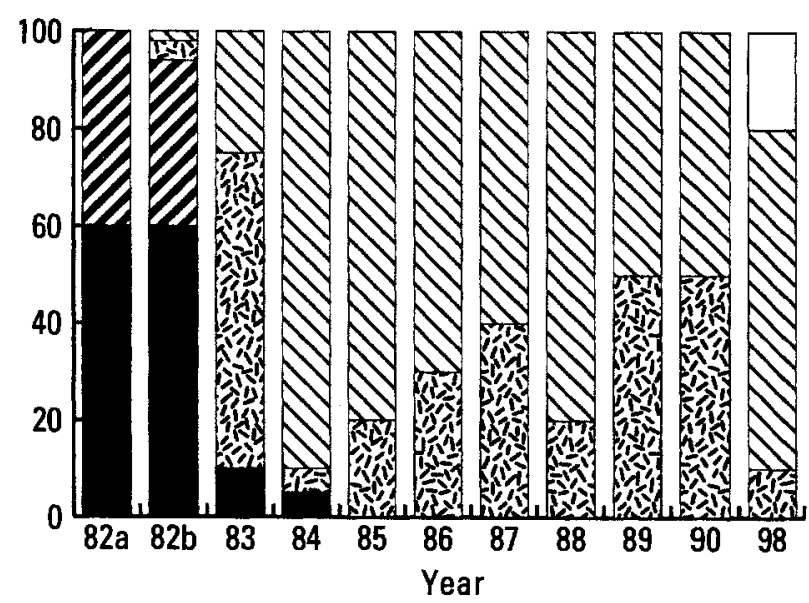

PLOT 4 (High density seabird colony)

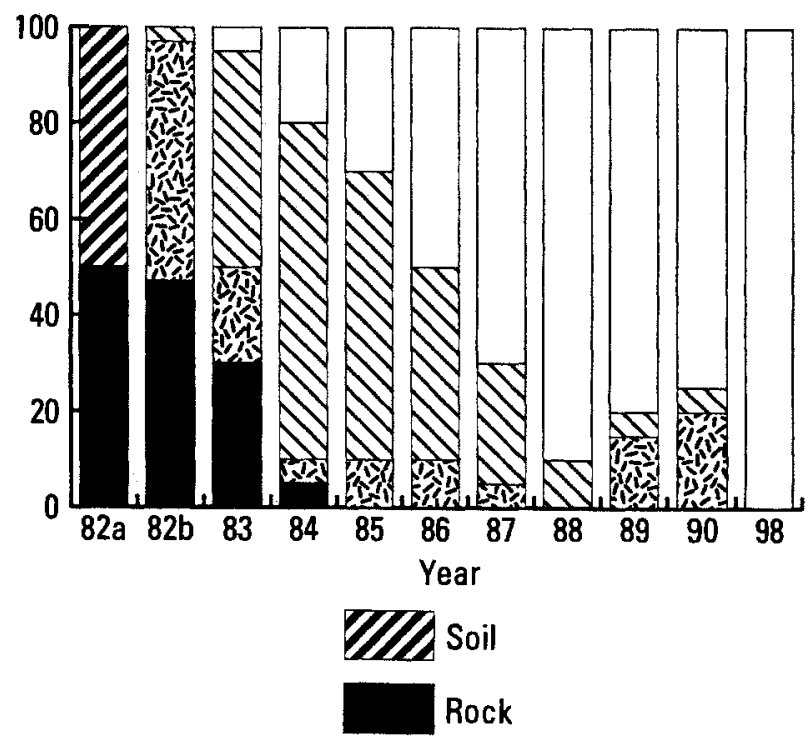

FIG. 3 - Total additive cover percentage of dominant species, soil and rock, measured at four sites between 1982 and 1998.

Colony B was densely covered in $P$. poiformis with scattered $S$. lautus. Burrowing habitat was stable. The invasion of Colony $\mathrm{B}$ by Colony A birds was not apparent in November 1982, but by mid January 1983 most of Colony B had been seriously damaged by excessive burrow-making. Most shearwater burrows were either empty or contained courting pairs of shearwaters. Presumably, competition for burrows was so intense that breeding attempts had failed.

By the following breeding season (1984) damage to vegetation was severe, with $P$. poiformis remaining in only isolated clumps, between which was bare soil no longer capable of supporting burrows, due to its fragility in the absence of plant root systems. Each evening, hundreds of adult shearwaters could be seen sitting on the surface, no longer making burrows to occupy. By the 1988 breeding season, destructive activity had diminished; $S$. lautus was flourishing in bare soil areas, with evidence of new $P$. poiformis growth. Burrow density had decreased by then from a pre-fire average of $0.59 / \mathrm{m}^{2}$ to $0.15 / \mathrm{m}^{2}$, or from about 350 to 90 burrows. The decrease in destructive activity in Colony $B$ coincided with the return of shearwaters to Colony A. Their return to Colony A, however, does not altogether explain the reduced damage, because only small numbers of birds are known to have returned to Colony A. 


\section{Inter-island Comparisons}

The shearwater colony on Little Dog Island (fig. 1) was estimated to contain 352000 burrows (Brothers \& Skira 1988), with an average occupancy rate by chicks of $64.7 \%$ (Skira \& Wapstra 1980). In early 1973, the whole colony was burned. Of 100 shearwater burrows examined several days after the fire, in March 1973, only 19 still contained chicks. Therefore, based on the average occupancy rate, $71 \%$ of chicks or 161900 died.

A number of dead adult shearwaters were also found in the colony but significant numbers would not have perished, because at this time of year few remain ashore during day time.

Once again, as at Albatross Island, the fire on Little Dog Island caused the least long-term damage to the shearwaters, owing to the fact that mostly chicks and not adults were involved. This was not the case on Cat Island (fig.1), where a fire that burned virtually the whole shearwater colony, in addition to an Australian gannet (Morus serrator) colony, occurred in early January 1984, at which time adult shearwaters were incubating. No occupied burrows were found here several days after the fire (pl. 4).

Forty-five or $33 \%$ of the 136 shearwater colonies listed in Naarding (1981) have been burnt in the last 15 years (see appendix), many of these more than once. This amounts to approximately $52 \%$ by area of shearwater colonies.

\section{DISCUSSION}

In terms of shearwater numbers affected, the fire on Albatross Island, although significant for this particular location, was of little consequence generally, because of the very large Tasmanian population distributed through many rookeries. Documenting the direct and indirect effects of this particular fire revealed some unexpected problems that fires can cause shearwaters. These are mostly due to the total destruction of nesting habitat, which is not typical of fires generally in shearwater colonies (N. Brothers, pers. obs.). Fires frequently burn rapidly through shearwater colonies, destroying all existing vegetation but causing little damage to soils. In such circumstances, existing $P$. poiformis tussocks are capable of regrowing. Nevertheless, such fires still cause considerable shearwater mortality.

For the prions, we think that there were adequate available nesting sites elsewhere on the island for those prions displaced by the fire to have re-established. This would account for them not making use of the area at the earliest opportunity. This supposition is supported by the observation of a significant increase in courting pairs of prions in nesting habitat adjacent to the burnt area that did not attempt breeding on the first and second seasons following the fire. The abundance of such birds subsequently diminished, presumably as they established new nesting sites.

The shearwaters' synchronised breeding habits, in common with many other species of seabirds, makes them particularly vulnerable to fires. If a fire should occur any time during the incubation period, it is highly likely that one bird of each pair will die and no chicks will be produced that year. It is possible that a high proportion of those killed will be of the same sex, owing to the synchrony of both egg-laying and subsequent parent-to-parent incubation shifts by adults. Apart from the fact that most shearwaters mate for life (unless their partner dies), the result of high adult death rate during incubation would be long-term disruption to the productivity of the colony. Such effects have not yet been studied, although the scant data available from Cat Island before and after the fire do give an indication of long-term effects of a fire occurring at a time when the greatest long-term damage to shearwater was likely. Warham (1979) assessed the burrow density on Cat Island before the fire at about $1 / \mathrm{m}^{2}$. Shearwaters and many other procellariforms cannot easily compensate for such dramatic high death rates of either adults or chicks, as each pair is only capable of producing one egg each year.

It could take many generations for a shearwater colony in which large numbers of adult birds died to regain normal productivity (Serventy \& Curry 1983). This would be especially so if, in normal circumstances, a colony's annual recruitment is equal to annual natural mortality. Puffinus tenuirostris is capable of breeding at five years of age (Serventy 1967) but most do not do so until about seven years of age (Skira 1991). Such factors as nesting-site availability could affect the average age of first breeding, so the death of large numbers of breeding adults in a fire may provide the opportunity for significantly more birds to commence breeding at a younger age. This is one way the species can increase productivity. Another way is by maintaining higher than average chick survival, which is not likely to be related to the effects of fires.

Like most burrow-nesting species of seabirds, shearwaters are particularly disinclined to emerge from the safety of burrows during daytime. As virtually all fires are lit during daytime and tend to burn very quickly through colonies, few adult shearwaters are likely to escape. Some appear to escape their burrows but experience difficulty in becoming immediately airborne from densely vegetated areas. The abundance of burned adults on the colony surface at the Cat Island fire is evidence of this. It was apparent during burrow inspection after the fire on Little Dog Island that survival of burrow occupants increased on sloping ground, where the burrows tend to be deeper and also the passage of fire could be more rapid (if the fire was burning uphill).

Destruction of nesting habitat, as occurred on Albatross Island, is another long-term consideration. Generally recurrence of a fire on a seabird breeding island is rare or at least irregular, which reduces considerably the likelihood of colony degeneration as a consequence of fire. Fire was a commonly used method of improving access to shearwater burrows, by reducing plant density, on islands subjected to commercial harvesting of shearwater chicks. It is still used today but not as frequently. Such fires to reduce Poa poiformis density were lit outside the breeding season and were actually considered to increase burrow densities.

However, it is more likely that the increase was an illusion created by burrows being more readily visible to bird harvesters. Such deliberate burning during winter, when birds are absent, is likely to have less impact on burrowing habitat than would a summer fire because, during winter, the soils tend not to burn, as they are invariably wet. This also means that the tussock roots are not killed, so regrowth is comparatively rapid, which prevents colonisation by plant species such as Senecio capillifolius. This species as well as $S$. lautus colonise disturbed areas rapidly in the environment of shearwater colonies. These plant species show a marked annual senescence and have less effective root systems than $P$. poiformis for stabilising soils and preventing excessive soil disturbance by birds. The Senecio 
species are less effective at preventing soil erosion in shearwater colonies, most of which are exposed to frequent, strong winds. S. capillifolius, which is apparently restricted to shearwater colonies (Kirkpatrick 1993), is possibly a fire ephemeral (Guiler et al. 1958).

Over a prolonged period, such fire management would undoubtedly have decreased shearwater burrow density through increased soil instability. This was noticeable even after one fire on both Little Dog and Cat Islands.

A number of shearwater breeding islands are also used for sheep and cattle grazing, and fire is used to generate new plant growth, so burning often occurred with no consideration for breeding seabirds. This practice is fortunately becoming less frequent.

The fire history of all shearwater colonies in Tasmania is very poorly documented, so it is not always possible to ascertain whether certain colonies were burnt, and if so when. There are several instances where it appears obvious that burrowing habitat degradation similar to that on Albatross Island has been caused by fire, yet no records exist of recent fires, nor are there prior burrow-density assessments from which population estimates could be made for comparison

The likelihood of a colony being burnt is influenced by the following factors. It is highly likely that any colony on mainland Tasmania, as opposed to offshore islands, will be burnt and perhaps more frequently than once in ten years. If adjacent to residential establishment, as a number of colonies are, the likelihood of fires is reduced. This is also true of those colonies on offshore islands where man has a "presence", such as lighthouses or other shipping navigation aids. Other colonies on offshore islands are protected somewhat from being burnt simply because they are remote and difficult for persons to visit. These localities contrast with those that are visited often by boat for recreational purposes.

\section{SUMMARY}

Fire on Albatross Island (1982) destroyed a colony of shorttailed shearwaters, incinerating at least 900 chicks. Some penguins died, but thousands of fairy prion chicks which fledge in February escaped destruction by a matter of weeks.

For the present study, post-fire vegetation recolonisation and soil formation were measured over 16 years at four plots on Albatross Island, and a succession of species was observed. One of the plots was indistinguishable from unburnt similar habitat on the island in its third year of regeneration. Poa poiformis and Senecio lautus were observed to be the climax species on this rookery. Over a nine-year period, four plots in burned vegetation on Albatross Island went from bare ground and soil to $100 \%$ Poa poiformis cover in two cases, a mixture of Poa poiformis, Disphyma crassifolium and Senecio lautus dominating the remaining two plots. Soil depth was found to increase rapidly where Poa poiformis was able to establish early dominance.

Differential recolonisation success, recorded amongst shearwaters, fairy prions and fairy penguins, was related to soil and vegetation recovery.

After the fire, fairy penguins successfully sought nesting sites elsewhere on the island, outisde the burnt area. Penguins slowly began to recolonise the burnt area two years after the fire, because they can exploit the smallest amount of nesting habitat.
Shearwaters displaced by the fire from Colony A sought to nest in unburned Colony $\mathrm{B}$, causing considerable damage to soil and vegetation. Competition for burrow space became so severe that breeding was probably affected. Six years after the fire, destructive activity diminished.

The effect of the fire on birds on Albatross Island was compared with a colony on Little Dog in the Furneaux Group. After the whole colony was burned in 1973, it was estimated that $71 \%$ of the chicks died. A large number of adults did not perish, because few adult shearwaters remain ashore during the day at this time of the year. As at Albatross Island, this fire caused the least long-term damage to shearwaters because mostly chicks were burned and not adults. In contrast, a fire on Cat Island in January 1984, completely destroyed the colony because the adult shearwaters were incubating.

Considerable mortality of birds can occur because of the shearwaters' synchronosed breeding habits. This makes them, in common with other species of seabirds, particularly vulnerable to fires. The long-term effect could be significant because each adult pair is only capable of producing one egg each year. A population could partly compensate by commencement of breeding at a younger age, and by maintaining higher than average chick survival.

Fires can cause total destruction of shearwater rookery habitat, but many deliberately lit fires in rookeries are cool winter burns which destroy standing vegetation but not soil or root structures. Burning muttonbird rookeries does not increase burrow density, but makes existing burrows more readily visible. Over a prolonged period, the winter burns decrease shearwater burrow density through increased soil instability.

Forty-five of Tasmania's 136 shearwater colonies have been burnt in the last 15 years, many of these more than once.

An assessment of risk of burning of all Tasmanian shearwater colonies shows that $21 \%$ of colonies are at high risk of being burnt, $26 \%$ are at moderate risk and $52 \%$ are considered to be at low risk of burning.

\section{ACKNOWLEDGEMENTS}

We thank the Toyota Foundation for their support of this project through the co-ordination of Professor N. Maruyama of Tokyo University of Agriculture and Technology. Neil Smith provided transport on Wild Wind to Albatross Island, without which the study would not have been possible. We thank all those who accompanied Nigel on the numerous visits to Albatross Island; your support and participation is appreciated. Irynej Skira undertook burrow occupancy assessment on Cat Island, information from which was included in this paper.

\section{REFERENCES}

Brothers, N.P. \& Skira, I.J., 1988: Little Dog Island, Furneaux Group, Tasmania - Seabird Island No. 185. Corella 12: 78-84.

Brown, M.J., Maruyama, N. \& Williams, K.J., 1993: Ecological studies of vegetation in short-tailed shearwater colonies in Tasmania. Pap. Proc. R. Soc. Tasm. 127: 11-16.

Gillham, M.E., 1960a: Vegetation of tern and gannet colonies in northern New Zealand with a comparative note on 
colonies in Bass Strait, Tasmania. Trans. R. Soc. NZ 88: 211-234.

Gillham, M.E., 1960b: Destruction of indigenous heath vegetation in Victorian sea-bird colonies. Aust. J. Bot. 8: $278-317$.

Guiler, E.R., Serventy, D.L. \& Willis, J.H., 1958: The Fisher Island field station - with an account of its principle flora and fauna. Pap. Proc. R. Soc. Tasm. 92: 165-174.

KiRKPATRICK, J.B., 1993: Dry coasral ecosystems of southeastern Australia. In van der Maarel, E. (Ed.): ECOSYSTEMS OF THE WORLD 2B. DRY COASTAL ECOSYSTEMS: AFRICA, AMERICA, ASIA AND OCEANIA. Elsevier, Amsterdam: 273-288.

NAARding, J.A., 1981: Study of the Short-tailed Shearwater, Puffinus tenuirostris in Tasmania. Wildl. Div. Tech. Rep. 81/3. National Parks and Wildlife Service, Tasmania.

Plomley, N., 1966: FRIENDL Y MISSION: THE TASMANIAN JOURNALS AND PAPERS OF GEORGE AUGUSTUS ROBINSON 1829-1834. Tasmanian Historical Research Association, Hobart.

SERVENTY, D.L., 1967: Aspects of the population ecology of the Short-tailed Shearwater, Puffinus tenuirostris. In Snow,
D.W. (Ed.): PROCEEDINGS OF THE XIV INTERNATIONAL ORNITHOLOGICAL CONGRESS.

SERVENTY, D.L. \& CuRrY, P.J., 1983: Observations of colony size, breeding success, recruitment and inter colony dispersal in a Tasmanian colony of Short-tailed Shearwaters, Puffinus tenuirostris over a 30 year period. Emu 84: 71-79.

SkIRA, I.J., 1991: The Short-tailed Shearwater: A review of its Biology. Corella 15: 45-52.

SkiRA, I.J. \& WAPSTRA, J.E., 1980: Occupation of burrows as a means of estimating the harvest of Short-tailed Shearwaters in Tasmania. Emu 80: 233-238.

Walsh, D., KirkpaTrick, J. B. \& SkIRA, I.J., 1997: Vegetation patterns, environmental correlates and vegetation change in a Puffinus tenuirostris breeding colony at Cape Queen Elizabeth, Tasmania. Aust. J. Bot. 45: 71-79.

WARHAM, J., 1979: Cat Island, Tasmania - Seabird Island No. 68. Corella 3: 42-45.

(accepted 5 July 1999)

\section{APPENDIX}

Tasmanian shearwater rookeries (and their areas) where there has been observed evidence of burning. The list begins with islands in the Furneaux Group, thereafter proceeding clockwise around Tasmania.

\begin{tabular}{|c|c|c|c|}
\hline Cat Island & 2 ha & Spectacle Island & $1 \mathrm{ha}$ \\
\hline Little Green Island & 2 ha & Betsey Island & 20 ha \\
\hline Big Dog Island & $40+$ ha & Cape Queen Elizabeth (north side) & $1 \mathrm{ha}$ \\
\hline Little Dog Island & 15 ha & Cape Queen Elizabeth (main rookery) & 9 ha \\
\hline Passage Island & 100 burrows & Pineapples & $5 \mathrm{ha}$ \\
\hline Preservation Island & 1000 burrows & Southport Island & v.small \\
\hline Chappell Island (part) & 10 ha & Actaeon Islands & $5 \mathrm{ha}$ \\
\hline Big Green Island & 2 ha & Cape Sorell (Trumpeter Rock) & 12 ha \\
\hline Kangaroo Island & 2 ha & Ocean Beach, Strahan & $10 \mathrm{ha}$ \\
\hline Prime Seal Island & very few & Hunter Island North & $6 \mathrm{ha}$ \\
\hline Settlement Point & 2 ha & Hunter Island South & $5 \mathrm{ha}$ \\
\hline Outer Sister Island & 800 burrows & Three Hummock Island & $140 \mathrm{ha}$ \\
\hline Inner Sister Island & 1500 burrows & Walkers Island & 56 ha \\
\hline Swan Island & 1 ha & Robbins Island (SE) & 4 ha \\
\hline George Rocks (off Eddystone) & 150 burrows & Robbins Island (N) & 2.5 ha \\
\hline St Helens Island & 1000 burrows & The Nut, Stanley & v. small \\
\hline Lachlan Island & & Ninth Island & 1.5 ha \\
\hline Blowhole, Maria Island & 11 ha & Waterhouse Island (N) & 0.5 ha \\
\hline Tasman Island ( $\&$ adjacent mainland) & 1 ha & Hunter Island West & $2.5 \mathrm{ha}$ \\
\hline Wedge Island & $10 \mathrm{ha}$ & Albatross Island & v. small \\
\hline Sloping Island & 20 ha & Christmas Island & $7.5 \mathrm{ha}$ \\
\hline Smooth Island (Dunalley) & $18 \mathrm{ha}$ & New Year Island & $25 \mathrm{ha}$ \\
\hline Fulham Island (Dunally) & 2 ha & & \\
\hline
\end{tabular}

